ICAASET-2021, 20-21 May, 2021, K.R. Mangalam University, Gurugram

International Journal of Technical Research \& Science (Special Issue) ISSN No.:2454-2024 (online)

\title{
GREY WOLF OPTIMIZATION TUNED TID AND I-TD CONTROLLERS FOR TRAJECTORY TRACKING OF DYNAMICAL AERIAL SYSTEM
}

\author{
Karan Sehgal, Manik Verma \\ E-Mail Id: karansehgal_2k18ee089@dtu.ac.in, manikverma0200@gmail.com \\ Delhi Technological University, Delhi, India
}

\begin{abstract}
The mathematical modelling and linearization of the laboratory non-linear aerial dynamical system, the Twin rotor MIMO system (TRMS), are presented in this paper. It can be used to solve real-world problems and to test the efficiency of controllers in control engineering. To achieve stable hovering conditions, a feedback control system with Tilted-Integral Derivative (TID) and Integral-Tilted Derivative (I-TD) controllers is linked within the continuous feedback loop for improving the control signal and varying the operational gains accordingly, taking into account high order nonlinearities and TRMS instability. Grey Wolf Optimization, a reliable and powerful metaheuristic evolutionary algorithm, is used to optimize the designed controllers. Manual disturbances are applied to both the yaw and pitch actuator angle stabilization controllers to validate their accuracy.
\end{abstract}

Keywords: Dynamical Aerial System, TID, I-TD, Grey Wolf Optimization, TRMS, Controller Design

\section{INTRODUCTION}

TRMS is a benchmarked experimental laboratory model of an unmanned aerial helicopter system that resembles or is called a prototype model. Pitch and yaw angle motion is controlled by two actuators driven by $12 \mathrm{~V}, 44-\mathrm{Watt}$ D.C. servomotors. They are positioned on both edges of the connecting beam, which is counterbalanced by an arm with adjusting weight at its ends [1]. The unknown dynamical characteristics increase system nonlinearities due to heavy cross-coupling among pitch and yaw rotors [2]. Several conventional and robust feedback controllers are designed to manage such complex systems. PID controllers are illustrated and chosen in dynamical systems due to their simple structural architecture [3]. The fractional-order PID controller is often used to stabilize TRMS to limit the deficiencies of integral and derivative schemes [4]. In addition, as shown in [5], [6], [7], the FOPID controller gains can be tuned using various nature-inspired multi-objective algorithms. Various modern and robust control strategies such as multiloop linear quadratic regulator [8], sliding mode [9], and robust H-infinity control [10] have been used. Another kind of fractional order PID controller known as Tilted Proportional Controller is proposed in [11] in line with these robust and modern controllers. TID controllers are used to controlling a variety of non-linear dynamical systems, including magnetic levitation [12] and two different types of LFC control [13]. The paper provides a unique comparison of TID and I-TD controls on laboratory aerial systems that have been benchmarked (TRMS). In addition, grey wolf optimization [14], [15] is used to tune the built controllers. The present paper is divided into five sections: Section I contains an introduction, section II contains mathematical modelling of TRMS, and section III contains Grey Wolf Optimized controller design and tuning. The precise comparison and graphical results are presented in Section IV, accompanied by conclusions and references.

\section{DYNAMICAL MODELLING OF THE BENCHMARKED AERIAL SYSTEM (TWIN ROTOR MIMO SYSTEM)}

The TRMS laboratory configuration, as shown in Fig. 2.1, is designed to mimic the characteristics of a helicopter, and has earned a reputation as a benchmarked device for research and development.

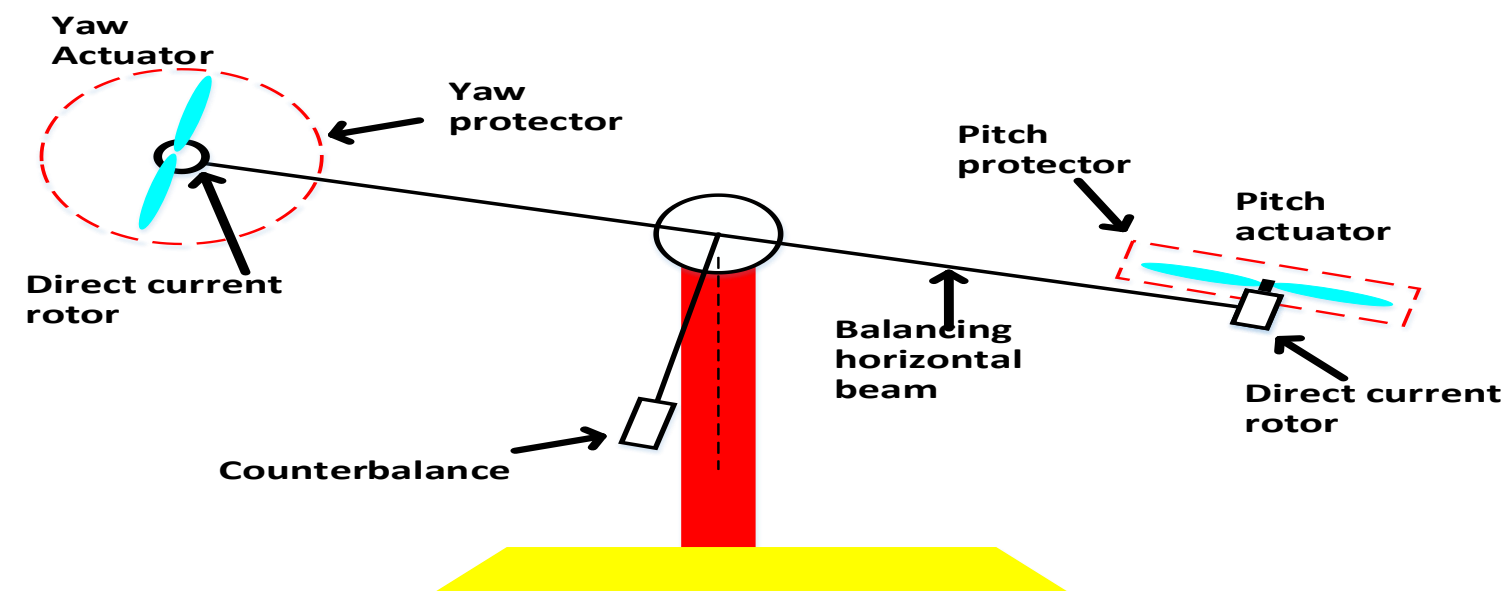

Fig. 2.1 Benchmarked laboratory aerial setup (TRMS)

The modelling equations of the Twin Rotor Aerial System (TRAS) for vertical hovering are given as equations (1) to (5). 
ICAASET-2021, 20-21 May, 2020, K.R. Mangalam University, Gurugram

International Journal of Technical Research \& Science (Special Issue)

ISSN No.:2454-2024 (online)

$$
\mathrm{I}_{1} \ddot{\psi}=\mathrm{W}_{1}-\mathrm{W}_{\mathrm{FG}}-\mathrm{W}_{\mathrm{B} \psi}-\mathrm{W}_{\mathrm{G}}
$$

Where,

$$
\begin{aligned}
& \mathrm{W}_{1}=\mathrm{a}_{1} \cdot \tau_{\mathrm{b}}+\mathrm{b}_{1} \tau_{\mathrm{a}} \text { are the nonlinear characteristics } \\
& \mathrm{W}_{\mathrm{FG}}=\mathrm{W}_{\mathrm{g}} \cdot \sin \psi \text { is gravity momentum } \\
& \mathrm{W}_{\mathrm{B} \psi}=\mathrm{B}_{1 \Psi} \cdot \psi+\mathrm{B}_{2 \psi} \cdot \operatorname{sign}(\dot{\psi}) \\
& \mathrm{W}_{\mathrm{G}}=\mathrm{K}_{\mathrm{gy}} \cdot \mathrm{M}_{1} \cdot \dot{\phi} \cdot \cos \psi \text { is gyroscopic momentum }
\end{aligned}
$$

The pitch actuator's electrical circuit is given by the s-domain transfer function in (6): $\tau_{\mathrm{a}}=\frac{\mathrm{k}_{1}}{\mathrm{~T}_{11}+\mathrm{T}_{10}} \cdot \mathrm{u}_{1}$

For horizontal hovering, the modelling equations are given as equations (7)-(9).

$$
\begin{aligned}
& \mathrm{I}_{2} \cdot \ddot{\phi}=\mathrm{W}_{2}-\mathrm{W}_{\mathrm{B} \phi}-\mathrm{W}_{\mathrm{R}} \\
& \mathrm{W}_{2}=\mathrm{a}_{2} \cdot \tau_{2}^{2}+\mathrm{b}_{2} \cdot \tau_{2} \\
& \mathrm{~W}_{\mathrm{B} \psi}=\mathrm{B}_{1 \phi} \cdot \dot{\psi}+\mathrm{B}_{2 \phi} \cdot \operatorname{sign}(\dot{\phi})
\end{aligned}
$$

Also, the cross-coupling moment $\mathrm{M}_{\mathrm{R}}$ is approximated as equation (10).

$$
\mathrm{W}_{\mathrm{CR}}=\frac{\mathrm{k}_{\mathrm{c}}\left(\mathrm{T}_{0} \mathrm{~s}+1\right)}{\mathrm{T}_{\mathrm{p}} \mathrm{s}+1} \cdot \tau_{1}
$$

The yaw DC actuator with a circuital loop in the s-domain momentum transfer function is described by equation (11).

$$
\tau_{b}=\frac{k_{2}}{T_{21} s+T_{20}} \cdot u_{2}
$$

On solving the equations (1) to (9), we obtain $d(\psi)$ and $d(\phi)$ for main and tail rotors given as equations (12) and (13) respectively.

$$
\begin{aligned}
& \mathrm{d}(\psi)=\frac{1}{\mathrm{I}_{1}}\left[-\int \mathrm{B}_{1} \cdot \psi \cdot d(\psi)+\int\left(0.0163 * \sin 2 \psi \cdot(\mathrm{d}(\phi))^{2}-\int\left(\mathrm{W}_{\mathrm{fg}} \cdot \sin \psi\right) \mathrm{dt}\right)\right] \\
& \mathrm{d}(\phi)=\frac{1}{\mathrm{I}_{2}}\left[-\int \mathrm{B}_{1} \cdot \phi \cdot d \phi+\int\left(\mathrm{b}_{1} \frac{1.1 \mathrm{u}_{1}}{1.2 \mathrm{~s}+1}+\mathrm{a}_{1}\left(\frac{1.1 \mathrm{u}_{1}}{1.2 \mathrm{~s}+1}\right)^{2}\right) \mathrm{dt}\right]
\end{aligned}
$$

After putting the system parameter values and constants in Table-1, a linearized state-space model transfer function of TRMS has been derived as equation (14)

$$
\mathrm{T}(\mathrm{s})==\left[\begin{array}{ll}
\mathrm{T}_{11}(\mathrm{~s}) & \mathrm{T}_{12}(\mathrm{~s}) \\
\mathrm{T}_{21}(\mathrm{~s}) & \mathrm{T}_{22}(\mathrm{~s})
\end{array}\right]=\left[\begin{array}{cc}
\frac{1.247}{(\mathrm{~s}+0.843)\left(\mathrm{s}^{2}+0.08624 \mathrm{~s}+4.707\right)} & 0 \\
\frac{1.472(\mathrm{~s}+0.2867)}{\mathrm{s}(\mathrm{s}+5)(\mathrm{s}+0.839)(\mathrm{s}+0.5)} & \frac{3.4}{\mathrm{~s}(\mathrm{~s}+5)(\mathrm{s}+1)}
\end{array}\right]
$$

The derived transfer functions for the pitch rotor are given as equation (15), and the two poles of the pitch transfer function are in RHS and cross the imaginary axis in the root locus plot in Fig. 2.2, indicating that the system is unstable as the system gain increases.

$$
\mathrm{T}(\mathrm{s})_{\mathrm{p}}=\frac{1.247}{\left.\mathrm{~s}^{4}+1.83 \mathrm{~s}^{3}+5.617 \mathrm{~s}^{2}+8.265 \mathrm{~s}+3.563\right)}
$$

\section{Table -2.1 Modelling Constants and Static Gains}

\begin{tabular}{|l|c|}
\hline TRMS modelling Constants & Values \\
\hline $\mathbf{I}_{\mathbf{1}}$ - Momentum of the Main actuator & $7.9 \times 10^{-2} \mathrm{Kgm}^{2}$ \\
\hline $\mathbf{I}_{\mathbf{2}}$ - Momentum of the Tail actuator & $4 \times 10^{-3} \mathrm{Kgm}^{2}$ \\
\hline $\mathbf{a}_{\mathbf{1}}$ - Main actuator Static Gain & 0.4134 \\
\hline $\mathbf{b}_{\mathbf{1}}$ - Main actuator Static Gain & 0.655 \\
\hline $\mathbf{a}_{\mathbf{2}}$ - Tail actuator Static Gain & 0.67 \\
\hline $\mathbf{b}_{\mathbf{2}}$ - Tail actuator Static Gain & 0.74 \\
\hline $\mathbf{W}_{\mathbf{g}}$ - Gravity Moment & 0.399 \\
\hline $\mathbf{B}_{\mathbf{1} \boldsymbol{\Psi}^{-}}$- Frictional Moment of Pitch Propeller & $5 \times 10^{-0.6}$ \\
\hline $\mathbf{B}_{\mathbf{2} \Psi^{-}}$- Frictional Moment of Pitch Propeller & $0.7 \times 10^{-0.6}$ \\
\hline
\end{tabular}


ICAASET-2021, 20-21 May, 2020, K.R. Mangalam University, Gurugram

International Journal of Technical Research \& Science (Special Issue) ISSN No.:2454-2024 (online)

\begin{tabular}{|l|c|}
\hline $\mathbf{B}_{\mathbf{1} \boldsymbol{\varphi}}$ - Friction Moment of Yaw Propeller & $2 \times 10^{-0.5}$ \\
\hline $\mathbf{B}_{\mathbf{2} \boldsymbol{\varphi}}$ - Friction moment of Yaw Propeller & $3.5 \times 10^{-0.5}$ \\
\hline $\mathbf{K}_{\mathbf{g y}}$ - Gyroscopic Moment & 0.053 \\
\hline $\mathbf{k}_{\mathbf{1}}$ - DC Constant in the Main actuator & 1.45 \\
\hline $\mathbf{k}_{\mathbf{2}}$ - DC Constant in the Tail actuator & 0.79 \\
\hline $\mathbf{T}_{\mathbf{1 1}}$ - Moment of the Main actuator & 1.01 \\
\hline
\end{tabular}

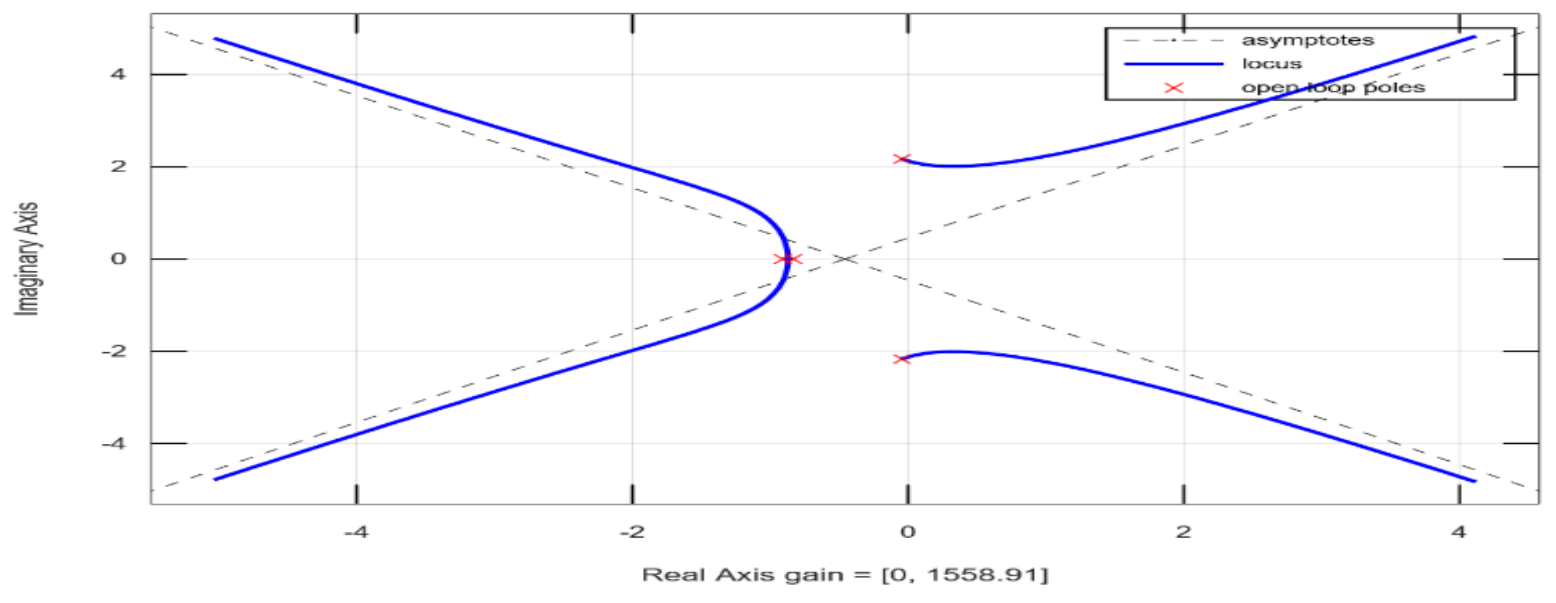

Root Locus or yav

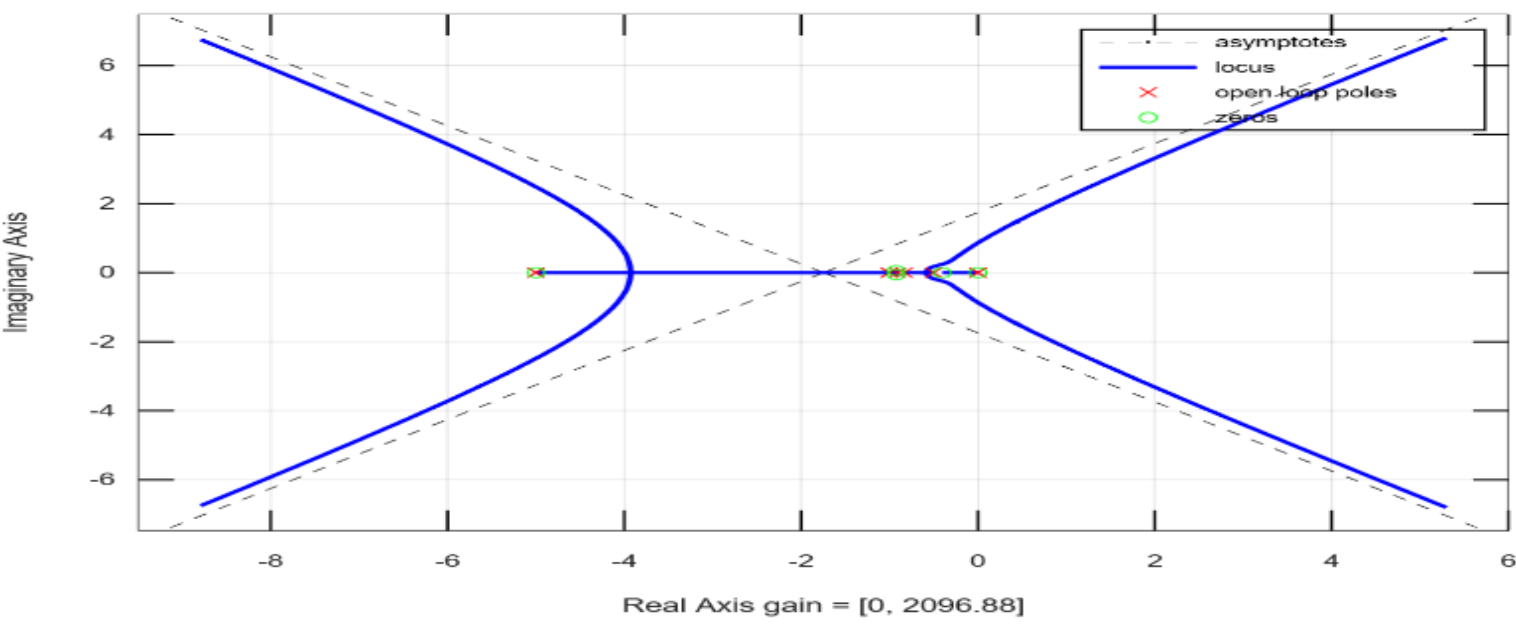

Fig. 2.2 Root Locus for pitch and yaw rotor respectively

The yaw rotor's transfer functions are given as equation (16). In the root locus plot in Fig. 2.2, the two poles of the yaw's transfer function are in RHS and cross the imaginary axis, showing that the system is unstable as the system gain increases.

$$
\mathrm{T}(\mathrm{s})_{\mathrm{y}}=\frac{4.362 \mathrm{~s}^{4}+31.66 \mathrm{~s}^{3}+56.24 \mathrm{~s}^{2}+36.61 \mathrm{~s}+7.569}{\mathrm{~s}^{8}+14.24 \mathrm{~s}^{7}+74.53 \mathrm{~s}^{6}+183 \mathrm{~s}^{5}+239 \mathrm{~s}^{4}+171.2 \mathrm{~s}^{3}+63.42 \mathrm{~s}^{2}+9.465 \mathrm{~s}}
$$

\section{DESIGNING AND OPTIMIZATION OF CONTROL SCHEMES}

The control problem and desired target for testing TID and I-TD controllers are optimal and precise trajectory tracking as well as fast stabilization control of yaw and pitch actuators. The error e $(\mathrm{t})$ between the setpoint and experimental trajectory is fed into both controllers, and the output is $\mathrm{c}(\mathrm{t})$, which is a regulated voltage signal for the aerial system's yaw and pitch actuators.

\subsection{Tilted Integral Derivative (TID) Controller Designing}

The TID controller's control scheme can be thought of as an upgraded fractional variant of the traditional IO-PID controller's control scheme, which has three tuneable gains tilted, integral, and derivative, which are denoted by the letters $\mathrm{k}_{\mathrm{t}}, \mathrm{k}_{\mathrm{i}}$, and $\mathrm{k}_{\mathrm{d}}$, respectively. Despite the standard PID controller, a fractional-order s-domain transfer function $\mathrm{s}^{1 / n}$ replaces the proportional control block, where $\mathrm{n}$ is a positive integer, the desired performance can be achieved by selecting the value of $n$. In the present paper, the value of $n$ has been empirically determined to be 3 . 
ICAASET-2021, 20-21 May, 2020, K.R. Mangalam University, Gurugram

International Journal of Technical Research \& Science (Special Issue) ISSN No.:2454-2024 (online)

Peak overshoot and settling time have been set at $4 \%$ and 8 seconds, respectively, to ensure smooth hovering and take-off of the aerial system in real-time. The TID controller's general output control equation and s-domain Laplace transfer function are given as equations (17) and (18).

$$
\begin{aligned}
& c(t)=k_{t} D^{\frac{-1}{n}} e(t)+k_{i} D^{-1} e(t)+k_{d} D^{1} e(t) \\
& U(s)=\frac{c(s)}{e(s)}=k_{t} s^{\frac{-1}{n}}+k_{i} s^{-1}+k_{d} s^{1}
\end{aligned}
$$

The schematic block diagram of the TID controller applied to TRMS with unity feedback system is shown in Fig.3.1.

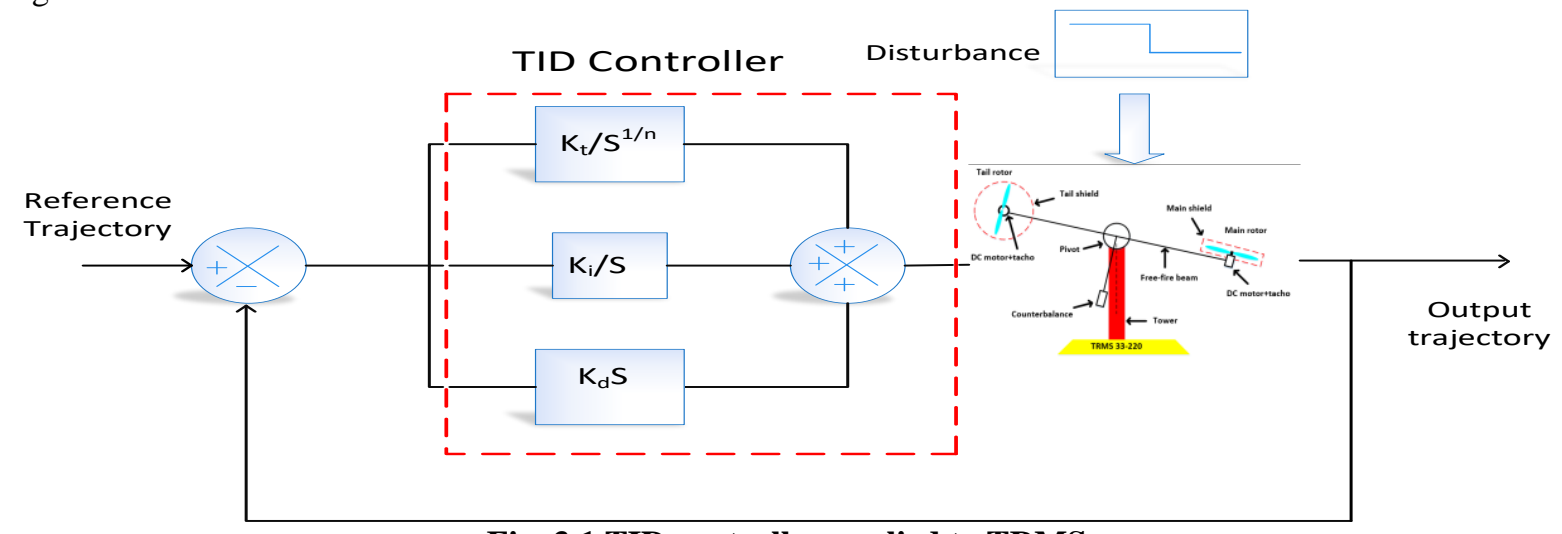

Fig. 3.1 TID controller applied to TRMS

The general characteristics equation is given as equation (19) by considering the aerial system with a TID controller applied with a unity feedback system.

$$
1+\mathrm{T}(\mathrm{s}) \mathrm{U}(\mathrm{s})=0
$$

The measured real and imaginary parts for pitch and yaw were given in equations (20-21) and (22-23), respectively, after substituting $\mathrm{s}_{12}=-0.5 \pm 0.518 \mathrm{i}$ and $\mathrm{n}=3$ in equations (19).

$$
\begin{aligned}
& \text { Real }_{\text {TIDp }}=1+1.93 \mathrm{k}_{\mathrm{tp}}-2.35 \mathrm{k}_{\mathrm{ip}}-1.59 \mathrm{k}_{\mathrm{dp}} \\
& \mathrm{Img}_{\text {TIDp }}=-1.19 \mathrm{k}_{\mathrm{tp}}-4.21 \mathrm{k}_{\mathrm{ip}}+6.58 \mathrm{k}_{\mathrm{dp}} \\
& \text { Real }_{\text {TIDy }}=1+9.25 \mathrm{k}_{\mathrm{ty}}-3.58 \mathrm{k}_{\mathrm{iy}}-5.57 \mathrm{k}_{\mathrm{dy}} \\
& \mathrm{Img}_{\text {TIDy }}=1.69 \mathrm{k}_{\mathrm{ty}}-1.24 \mathrm{k}_{\mathrm{iy}}-4.27 \mathrm{k}_{\mathrm{dy}}
\end{aligned}
$$

The final objective function $\mathrm{f}_{\text {TIDp }}$ and $\mathrm{f}_{\text {TIDy }}$ for pitch and yaw of the TID, the controller is obtained by substituting the values of $\operatorname{Real}_{\text {TIDp }}, \operatorname{Img}_{\text {TIDp }}$, Real $_{\text {TIDy }}$, Img ${ }_{\text {TIDy }}$ and used to calculate the optimal operational gains for pitch and for yaw actuators, when tuned by grey wolf optimization.

$$
\begin{aligned}
& \mathrm{f}_{\mathrm{TIDp}}=\mid \text { Real }_{\mathrm{TID}}|+| \mathrm{Img}_{\mathrm{TID}}\left|+\tan ^{-1}\right| \frac{\text { Real }_{\mathrm{TID}}}{\mathrm{Img}_{\mathrm{TID}}} \mid \\
& \mathrm{f}_{\text {TIDp }}=\left|1+1.93 \mathrm{k}_{\mathrm{tp}}-2.35 \mathrm{k}_{\mathrm{ip}}-1.59 \mathrm{k}_{\mathrm{dp}}\right|+\left|-1.19 \mathrm{k}_{\mathrm{tp}}-4.21 \mathrm{k}_{\mathrm{ip}}+6.58 \mathrm{k}_{\mathrm{dp}}\right|+ \\
& \tan ^{-1}\left|\frac{1+1.93 \mathrm{k}_{\mathrm{tp}}-2.35 \mathrm{k}_{\mathrm{ip}}-1.59 \mathrm{k}_{\mathrm{dp}}}{-1.19 \mathrm{k}_{\mathrm{tp}}-4.21 \mathrm{k}_{\mathrm{ip}}+6.58 \mathrm{k}_{\mathrm{dp}}}\right| \\
& \left|\operatorname{Img}_{\text {TIDy }}\right|+\tan ^{-1}\left|\frac{\text { Real }_{\text {TIDy }}}{\operatorname{Img}_{\text {TIDy }}}\right| \\
& \mathrm{f}_{\text {TIDy }}=\left|1+9.25 \mathrm{k}_{\mathrm{ty}}-3.58 \mathrm{k}_{\mathrm{iy}}-5.57 \mathrm{k}_{\mathrm{dy}}\right|+\left|1.69 \mathrm{k}_{\mathrm{ty}}-1.24 \mathrm{k}_{\mathrm{iy}}-4.27 \mathrm{k}_{\mathrm{dy}}\right|+ \\
& \tan ^{-1}\left|\frac{1+9.25 \mathrm{k}_{\mathrm{ty}}-3.58 \mathrm{k}_{\mathrm{iy}}-5.57 \mathrm{k}_{\mathrm{dy}}}{1.69 \mathrm{k}_{\mathrm{ty}}-1.24 \mathrm{k}_{\mathrm{iy}}-4.27 \mathrm{k}_{\mathrm{dy}}}\right| \\
& \text { (25) } \quad \mathrm{f}_{\mathrm{TIDy}}=\mid \text { Real }_{\text {TIDy }} \mid+
\end{aligned}
$$

\subsection{Integral -Tilted Derivative (I-TD) controller Designing Formulas}

The I-TD controller for TRMS is designed similarly to the TID controller, with the exception that the tilted and derivative blocks are held in feedback to the reference trajectory, and the integral block's voltage control signal is directly given to the aerial device, as shown in Fig. 3.2.

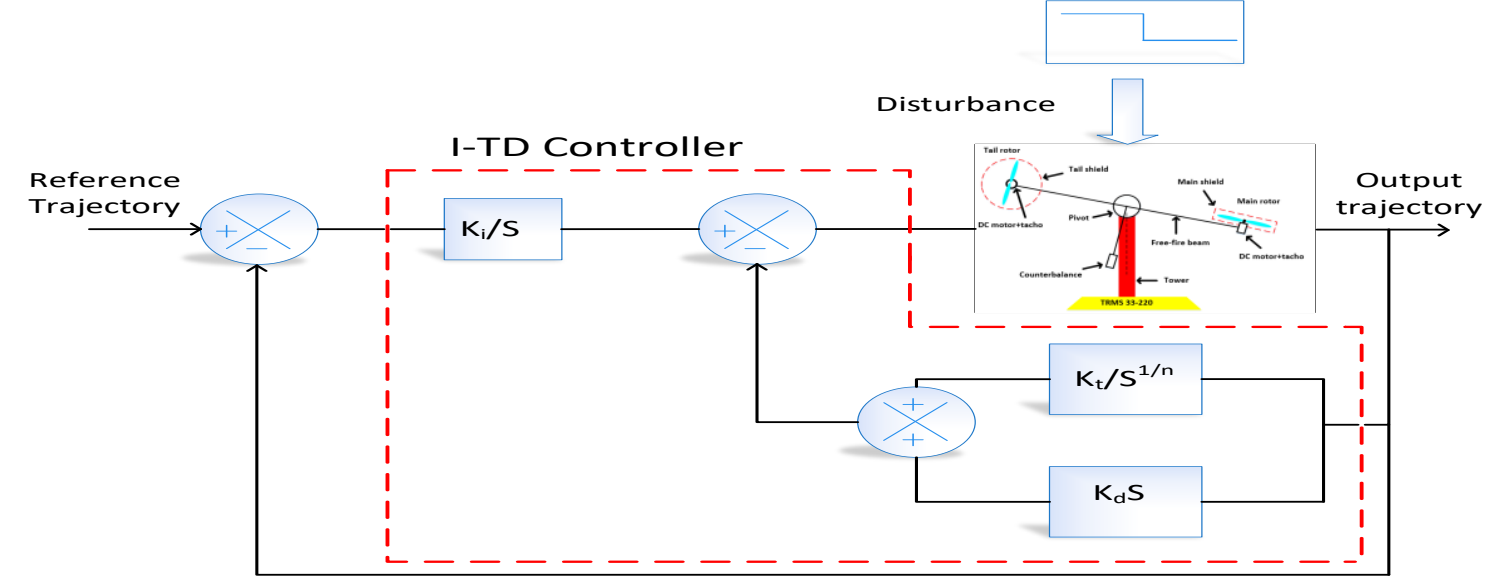

Fig. 3.2 I-TD controller applied to TRMS

DOI Number: https://doi.org/10.30780/specialissue-ICAASET021/004 
ICAASET-2021, 20-21 May, 2020, K.R. Mangalam University, Gurugram

International Journal of Technical Research \& Science (Special Issue) ISSN No.:2454-2024 (online)

Also, the controller output in time and the Laplace domain are given as equations (28) and (29).

$$
\begin{aligned}
& c(t)=k_{i} D^{-1} e(t)-\left(k_{t} D^{\frac{-1}{n}} e(t)+k_{d} D^{1} e(t)\right) \\
& U(s)=\frac{c(s)}{e(s)}=k_{i} s^{-1}-\left(k_{t} s^{\frac{-1}{n}}+k_{d} s^{1}\right)
\end{aligned}
$$

The measured real and imaginary parts for pitch and yaw for I-TD controllers are given in equations (30-31) and (32-33), respectively, by substituting the value of the dominant pole $\mathrm{s}_{12}=-0.5 \pm 0.518 \mathrm{i}$ and $\mathrm{n}=3$ in the characteristic equation.

$$
\begin{aligned}
& \operatorname{Real}_{\text {I-TDp }}=1-1.93 \mathrm{k}_{\mathrm{tp}}-2.35 \mathrm{k}_{\mathrm{ip}}+1.59 \mathrm{k}_{\mathrm{dp}} \\
& \mathrm{Img}_{\mathrm{I}-\mathrm{TDp}}=1.19 \mathrm{k}_{\mathrm{tp}}-4.21 \mathrm{k}_{\mathrm{ip}}-6.58 \mathrm{k}_{\mathrm{dp}} \\
& \operatorname{Real}_{\text {I-TDy }}=1-9.25 \mathrm{k}_{\mathrm{ty}}+3.58 \mathrm{k}_{\mathrm{iy}}+5.57 \mathrm{k}_{\mathrm{dy}} \\
& \operatorname{Img}_{\text {I-TDy }}=-1.69 \mathrm{k}_{\mathrm{ty}}-1.24 \mathrm{k}_{\mathrm{iy}}+4.27 \mathrm{k}_{\mathrm{dy}}
\end{aligned}
$$

The final objective function $\mathrm{f}_{\mathrm{I}-\mathrm{TD}}$ and $\mathrm{f}_{\mathrm{I}-\mathrm{TDy}}$ for pitch and yaw of the I-TD controllers are obtained by substituting the values of $\operatorname{Real}_{\mathrm{I}-\mathrm{TDp}}, \mathrm{Img}_{\mathrm{I}-\mathrm{TDp}}, \mathrm{Real}_{\mathrm{I}-\mathrm{TDy}}, \mathrm{Img}_{\mathrm{I}-\mathrm{TDy}}$ and used to calculate the optimal operational gains for pitch and for yaw actuators, when tuned by grey wolf optimization.

$$
\begin{aligned}
& \mathrm{f}_{\mathrm{I}-\mathrm{TDp}}=\left|\operatorname{Real}_{\mathrm{I}-\mathrm{TD}}\right|+\left|\operatorname{Img}_{\mathrm{I}-\mathrm{TD}}\right|+\tan ^{-1}\left|\frac{\text { Real }_{\mathrm{I}-\mathrm{TD}}}{\mathrm{Img}_{\mathrm{I}-\mathrm{TD}}}\right| \\
& \mathrm{f}_{\mathrm{I}-\mathrm{TDp}}=\left|1-1.93 \mathrm{k}_{\mathrm{tp}}-2.35 \mathrm{k}_{\mathrm{ip}}+1.59 \mathrm{k}_{\mathrm{dp}}\right|+\left|1.19 \mathrm{k}_{\mathrm{tp}}-4.21 \mathrm{k}_{\mathrm{ip}}-6.58 \mathrm{k}_{\mathrm{dp}}\right|+ \\
& \tan ^{-1}\left|\frac{1-1.93 \mathrm{k}_{\mathrm{tp}}-2.35 \mathrm{k}_{\mathrm{ip}}+1.59 \mathrm{k}_{\mathrm{dp}}}{1.19 \mathrm{k}_{\mathrm{tp}}-4.21 \mathrm{k}_{\mathrm{ip}}-6.58 \mathrm{k}_{\mathrm{dp}}}\right| \\
& \mathrm{f}_{\mathrm{I}-\mathrm{TDy}}=\left|\mathrm{Real}_{\mathrm{I}-\mathrm{TDy}}\right|+\left|\mathrm{Img}_{\mathrm{I}-\mathrm{TDy}}\right|+\tan ^{-1}\left|\frac{\text { Real }_{\mathrm{I}-\mathrm{TDy}}}{\text { Img }_{\mathrm{I}-\mathrm{TDy}}}\right| \\
& \mathrm{f}_{\mathrm{I}-\mathrm{TDy}}=\left|1-9.25 \mathrm{k}_{\mathrm{ty}}+3.58 \mathrm{k}_{\mathrm{iy}}+5.57 \mathrm{k}_{\mathrm{dy}}\right|+\left|-1.69 \mathrm{k}_{\mathrm{ty}}-1.24 \mathrm{k}_{\mathrm{iy}}+4.27 \mathrm{k}_{\mathrm{dy}}\right|+ \\
& \tan ^{-1}\left|\frac{1-9.25 \mathrm{k}_{\mathrm{ty}}+3.58 \mathrm{k}_{\mathrm{iy}}+5.57 \mathrm{k}_{\mathrm{dy}}}{-1.69 \mathrm{k}_{\mathrm{ty}}-1.24 \mathrm{k}_{\mathrm{iy}}+4.27 \mathrm{k}_{\mathrm{dy}}}\right|
\end{aligned}
$$

\subsection{Controllers Tuning by Grey Wolf Optimization (GWO)}

Recently, nature-inspired computational algorithms have gained a lot of traction in control engineering because they are based on predatory activities such as searching, hunting, pollinating, and so on. One of these natureinspired algorithms is Grey Wolf Optimization. It considers hunting and the social hierarchy of the grey wolf. It is used to optimize the controller parameters and minimizing the cost function. As shown in Fig. 3.3, grey wolves are treated as top prey predators and are categorised as alpha, beta, and omega based. The alpha wolf is considered the squad leader and has the authority to make major decisions such as the solution finding area and hunting. Beta wolves help and obey the alpha wolf's hunting orders, and they control the omega wolf, which is the lowest in the hierarchy.
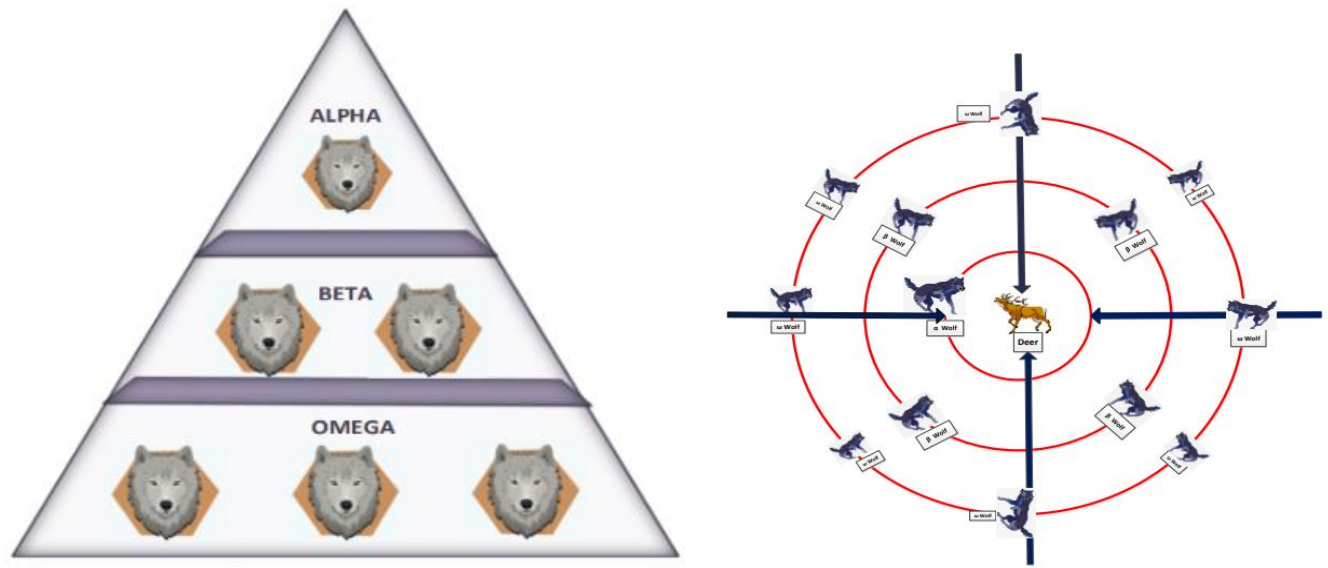

Fig. 3.3 Triangular hierarchy of alpha, beta, and omega wolves and hunting map of grey wolves

Equations are used to model the statistical modelling of encircling the prey (38-47).

Dist $=\mid$ B. $Y_{S}(\mathrm{i})-\mathrm{Y}(\mathrm{i}) \mid$

$\mathrm{Y}(\mathrm{i}+1)=\mathrm{Y}_{\mathrm{S}}(\mathrm{i})-\mathrm{A}$. Dist

$\mathrm{A}=2 \mathrm{ax}_{1}-\mathrm{a}$

$\mathrm{B}=2 \cdot \mathrm{x}_{2}$

Here $A, B$, and $Y_{s}, Y$ denote vector coefficients and the position of hunting set points as well as the location of the wolf. $x_{1}, x_{2}$ are randomized numbers ranging from 0 to 1 . Equations (42) to (47) show how to recognise alpha, beta, and omega wolves.

Dist $_{\alpha}=\left|B_{1} \cdot Y_{\alpha}(i)-Y(i)\right|$

$\mathrm{Y}_{11}=\mathrm{Y}_{\alpha}(\mathrm{i})-\mathrm{A}_{1}$. Dist $_{\alpha}$

$\operatorname{Dist}_{\beta}=\left|B_{2} \cdot Y_{\beta}(i)-Y(i)\right|$

$\mathrm{Y}_{12}=\mathrm{Y}_{\beta}(\mathrm{i})-\mathrm{A}_{2} \cdot$ Dist $_{\beta}$

$\operatorname{Dist}_{\omega}=\left|B_{3} . Y_{\omega}(i)-Y(i)\right|$

DOI Number: https://doi.org/10.30780/specialissue-ICAASET021/004 
ICAASET-2021, 20-21 May, 2020, K.R. Mangalam University, Gurugram

International Journal of Technical Research \& Science (Special Issue)

ISSN No.:2454-2024 (online)

$\mathrm{Y}_{13}=\mathrm{Y}_{\omega}(\mathrm{i})-\mathrm{A}_{3}$. Dist $_{\omega}$

The modelled minimising cost function of TRMS implanted through GWO via equation (18) for TID Controller for pitch and yaw actuators is reflected in equations (48) and (49), respectively.

Dist $_{\alpha / \omega / \beta}=\min \left|\mathrm{f}_{\mathrm{TIDp}}\right|$

$\operatorname{Dist}_{\alpha / \omega / \beta}=\min \left|\mathrm{f}_{\mathrm{TIDy}}\right|$

The minimising cost function for the I-TD controller is given as equations (50) and (51) for pitch and yaw controllers, respectively.

$\operatorname{Dist}_{\alpha / \omega / \beta}=\min \left|f_{I-T D p}\right|$

Dist $_{\alpha / \omega / \beta}=\min \left|f_{I-T D y}\right|$

From equations (43), (45), and (47), the best hunter wolf giving optimal solution is given as equation (52).

$\mathrm{Y}(\mathrm{i}+1)=\left(\mathrm{Y}_{11}+\mathrm{Y}_{12}+\mathrm{Y}_{13}\right) / 3$

Table-3.1 Pseudocode of GWO

\begin{tabular}{|c|c|}
\hline Step Performed & Algorithm \\
\hline $\begin{array}{c}\text { Initialization of } \\
\text { Optimization }\end{array}$ & $\begin{array}{c}\text { Dimension of the particular complication } \\
\text { Limitation of the particular complication } \\
\text { Size of Population } \\
\text { Optimizing Variable }\end{array}$ \\
\hline START & Limit condition (max - loops compiled or required permit error) \\
\hline FINDING & Regions of all of $\alpha, \beta, \omega$ wolves \\
& While not stop condition, Obtain the updated cost-minimizing function \\
& Upgrade the wolf regions \\
& Restrict the area of the coordinates \\
& Update $\alpha, \beta, \omega$ and also \\
& Upgrade the limiting condition \\
& Stop \\
\hline
\end{tabular}

After optimization by GWO, the optimized values of operational gains for TID and conventional I-TD controllers are provided in Table-3.2 and Table-3,3, respectively.

Table 3.2 I-TD Controller values

\begin{tabular}{|c|c|c|}
\hline \multirow{2}{*}{ ROTOR } & Control Variables & GWO Tuned values \\
\hline \multirow{3}{*}{ PITCH } & $\mathrm{k}_{\mathrm{tp}}$ & 4.39 \\
\cline { 2 - 3 } & $\mathrm{k}_{\mathrm{ip}}$ & 6.32 \\
\cline { 2 - 3 } & $\mathrm{k}_{\mathrm{dp}}$ & 18.87 \\
\hline \multirow{3}{*}{ YAW } & $\mathrm{k}_{\mathrm{ty}}$ & 14.98 \\
\cline { 2 - 3 } & $\mathrm{k}_{\mathrm{iy}}$ & 12.33 \\
\cline { 2 - 3 } & $\mathrm{k}_{\mathrm{dy}}$ & 25.23 \\
\hline
\end{tabular}

Table-3.3. TID Controller values

\begin{tabular}{|c|c|c|}
\hline \multirow{2}{*}{ ROTOR } & Control Variables & GWO Tuned values \\
\hline \multirow{3}{*}{ PITCH } & $\mathrm{k}_{\mathrm{tp}}$ & 5.45 \\
\cline { 2 - 3 } & $\mathrm{k}_{\mathrm{ip}}$ & 8.23 \\
\cline { 2 - 3 } & $\mathrm{k}_{\mathrm{dp}}$ & 17.95 \\
\hline \multirow{3}{*}{ YAW } & $\mathrm{k}_{\mathrm{ty}}$ & 16.82 \\
\cline { 2 - 3 } & $\mathrm{k}_{\mathrm{iy}}$ & 17.42 \\
\cline { 2 - 3 } & $\mathrm{k}_{\mathrm{dy}}$ & 29.52 \\
\hline
\end{tabular}

\section{RESULTS AND VALIDATION OF CONTROLLER}

Both TID and I-TD grey wolf tuned controllers have been experimentally tested and validated in real-time with optimally tuned operational gains provided in Table-3.1 and Table-3.2. Fig.4.1 and Fig.4.2 show the main and tail rotor response for the I-TD controller over the desired pitch angle considered as a reference trajectory.

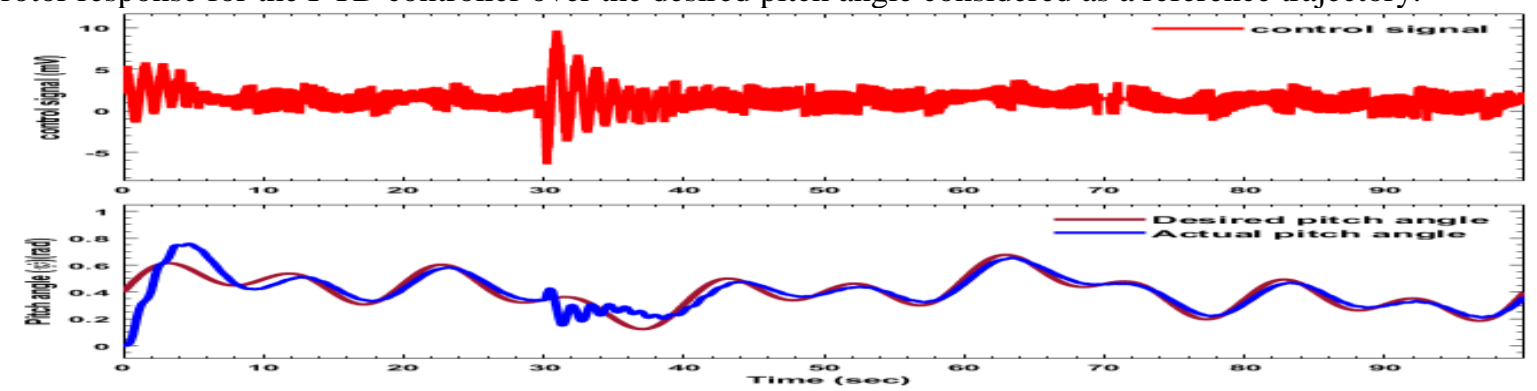

Fig. 4.1 I-TD controller pitch response

DOI Number: https://doi.org/10.30780/specialissue-ICAASET021/004

Paper Id: IJTRS-ICAASET2021-004

pg. 25

(a)2017, IJTRS All Right Reserved, www.ijtrs.com 
ICAASET-2021, 20-21 May, 2020, K.R. Mangalam University, Gurugram

International Journal of Technical Research \& Science (Special Issue) ISSN No.:2454-2024 (online)

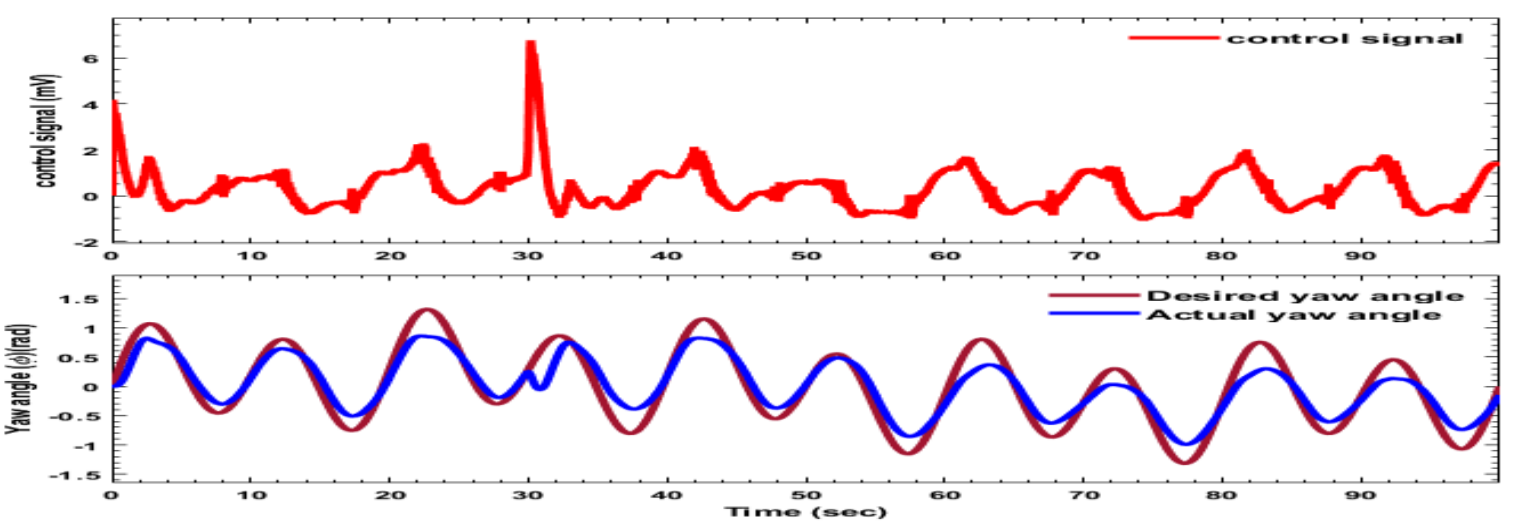

Fig. 4.2 I-TD controller yaw response

Fig. 4.3 and Fig. 4.4 show the main and tail rotor response for the TID controller, respectively. Also, the TID controller's control signals are displayed to observe controller performance in the time domain.
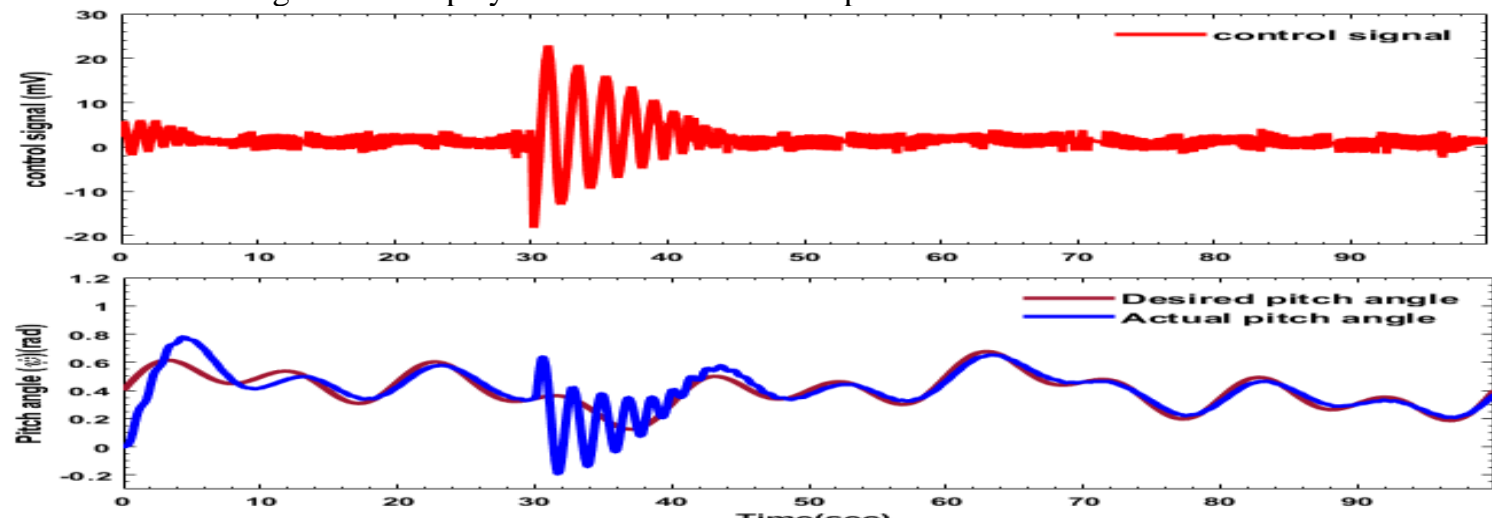

Fig. 4.3 TID controller pitch response
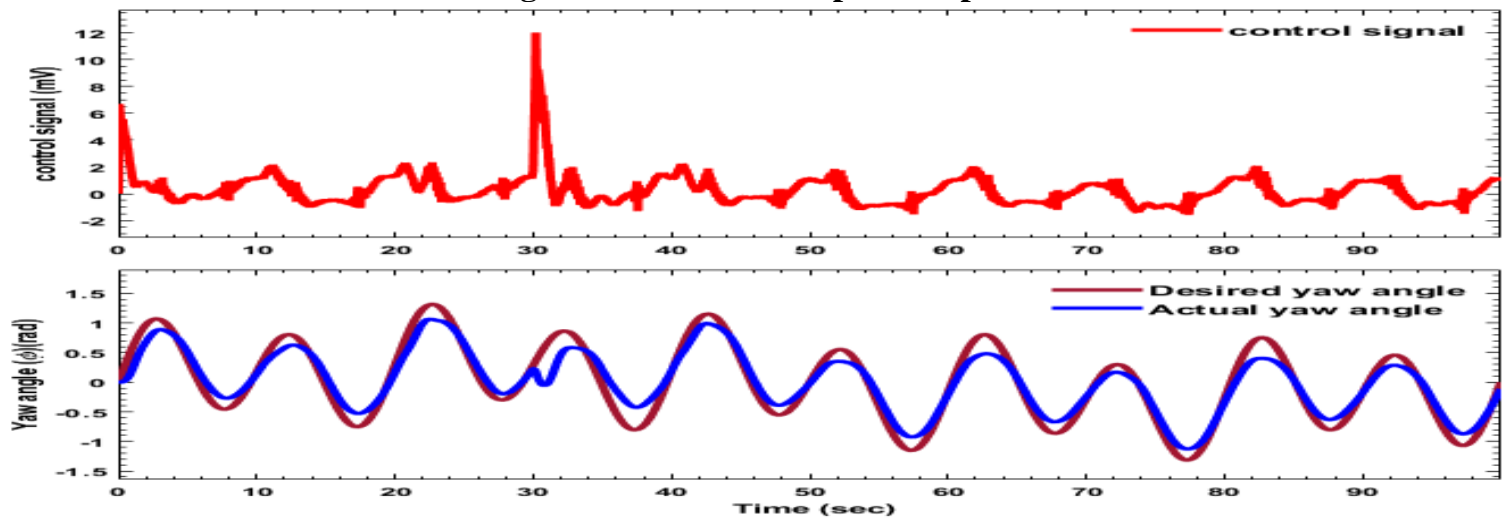

Fig. 4.4 TID controller yaw response

The I-TD controller outperforms the TID controller in terms of trajectory tracking for given reference waves, according to the controller's responses. Tables 4.1 and 4.2 show the responses of engineered controllers in terms of time to stabilise after a 30th-second manual disturbance. These given manual disturbances are of a random magnitude and resemble real-time atmospheric disturbances on the unmanned aerial system.

Table-4.2 TID Controller Values

\begin{tabular}{|c|c|c|c|}
\hline Rotor & Disturbance at (Sec) & Stabilization at (Sec) & Settling time (Sec) \\
\hline Pitch & $30^{\text {th }}$ & $44^{\text {th }}$ & 14 \\
\hline Yaw & $30^{\text {th }}$ & $33^{\text {th }}$ & 3 \\
\hline
\end{tabular}

Table-4.3 I-TD Controller values

\begin{tabular}{|c|c|c|c|}
\hline Rotor & Disturbance at (Sec) & Stabilization at (Sec) & Settling time (Sec) \\
\hline Pitch & $30^{\text {th }}$ & $40^{\text {th }}$ & 10 \\
\hline Yaw & $30^{\text {th }}$ & $32^{\text {th }}$ & 2 \\
\hline
\end{tabular}

\begin{tabular}{|c|c|c|}
\hline \multicolumn{3}{|c|}{ Table-4.4 Performance of TID \& I-TD w.r.t PID } \\
\hline Rotor & $\begin{array}{c}\text { TID } \\
\text { (\% faster than PID) }\end{array}$ & $\begin{array}{c}\text { I-TD } \\
\text { (\% faster than PID) }\end{array}$ \\
\hline Pitch & 44 & 60 \\
\hline Yaw & 25 & 50 \\
\hline
\end{tabular}

DOI Number: https://doi.org/10.30780/specialissue-ICAASET021/004

pg. 26

Paper Id: IJTRS-ICAASET2021-004

@2017, IJTRS All Right Reserved, www.ijtrs.com 
Table-4.4 shows the percentage of time that TID and I-TD controllers outperform the regular PID tuned with grey wolf optimization. The I-TD controller stabilises the system response faster than the TID controller for vertical motion by pitch rotor. The I-TD controller's increased stability is due to a continuous closed feedback loop of Tilted and Derivative blocks, which increases the control signal.

\section{CONCLUSION}

TID and I-TD controllers are compared in this paper for the first time. The benchmarked aerial dynamical system's stabilization is controlled by two TID and I-TD controllers for pitch/main and yaw/tail actuators. A bio-inspired grey wolf optimization algorithm is used to improve the efficiency of both the designed controllers. Both controllers were given manual disruptions every 30 seconds, and the time it took them to stabilize and return to the reference trajectory was measured experimentally. The mathematical comparison and trajectory monitoring graphs show that the I-TD controller takes less time to stabilize after a disturbance and performs better in terms of trajectory stabilization and tracking control.

\section{REFERENCES}

[1] Feedback Instruments, “Twin Rotor Mimo System,” 2016.

[2] P. China, D. Dutta, and M. R. Kumar 2020 Modelling of Twin Rotor MIMO System using Differential Evolution with Success-based Parameter Adaptation Proc. 1st Int. Conf. on Power, Control and Computing Technologies (Raipur) pp 223-28.

[3] S. K. Valluru, R. Kumar and R. Kumar 2019 Design and Implementation of L-PID and IO-PID Controllers for Twin Rotor MIMO System Proc. Int. Conf. on Power Electronics, Control, and Automation (New Delhi)

[4] S. K. Valluru, R. Kumar and Ayush 2019 Trajectory Tracking Control of TRMS using FO-PID and FOI-PD Controllers: An Experiment Proc. 3rd Int. Conf. on Recent Developments in Control, Automation \& Power Engineering (Noida) pp 319-22

[5] S. K. Valluru, R. Kumar and R. Kumar 2020 Design and Real Time implementation of fmincon, MOGA tuned IO-PID and FO-PI $\lambda \mathrm{D} \mu$ Controllers for Stabilization of TRMS Procedia Computer Science vol $171 \mathrm{pp}$ 1241-50

[6] S. K. Valluru and M. Singh 2017 Investigation of NARMA L-2 and Artificial Bee Colony Tuned PID Controllers for Bench Scaled Nonlinear Dynamical System Int. J. Control Theory Appl. vol 10 no. 6 pp 36374

[7] H. Prabha and R. Kumar 2020 Real Time Experimental control and Design of FOPI $\lambda$ and L-PID Controllers tuned by Invasive weed optimization for Trajectory Control of TRAS Proc. Int. Conf. on Power Electronics \& IoT Applications in Renewable Energy and its Control (Mathura) pp 148-52

[8] S.Valluru, M. Singh, Ayush, and A. Dharavath 2019 Design and Experimental Implementation of Multiloop LQR, PID, and LQG Controllers for the Trajectory Tracking Control of Twin Rotor MIMO System Intelligent Communication, Control and Devices vol 989, ed Choudhury S., Mishra R., Mishra R., Kumar A. (Singapore: Springer Nature) pp 599-608.

[9] P. U. Shaikh and S. Karvekar 2016 Implementation of Sliding Mode Controller for Twin Rotor Multi Input Multi Output System without state observer Proc. IEEE 1st Int. Conf. on Power Electronics, Intelligent Control and Energy Systems (Delhi) pp 1-6

[10] Ayush, H. Prabha and R. Kumar 2020 Robust Hळ Control Approach for Trajectory Tracking of Twin Rotor MIMO System Proc. Int. Conf. on Emerging Trends in Communication, Control and Computing pp 1-4

[11] Lurie, B.J. 1994 Three-parameter tunable tilt-integral-derivative (TID) controller U.S. Patent

[12] D. Sain, S. K. Swain and S. K. Mishra 2016 TID and I-TD controller design for magnetic levitation system using genetic algorithm Perspectives in Science vol 8 pp 370-73

[13] P. N. Topno and S. Chanana 2015 Tilt Integral Derivative control for two-area load frequency control problem Proc. 2nd International Conference on Recent Advances in Engineering \& Computational Sciences (Chandigarh) pp 1-6

[14] Mirjalili S, Mirjalili SM, Lewis A 2014 Grey wolf optimizer Advances in Engg. Software 69:46-61.

[15] H. Prabha, Ayush, R. Kumar, A.L. Meena. 2021 Real-Time Stabilization Control of Helicopter Prototype by IO-IPD and L-PID Controllers Tuned Using Gray Wolf Optimization Method Computational Methods and Data Engineering. Advances in Intelligent Systems and Computing vol 1227, ed Singh V., Asari V., Kumar S., Patel R. (Singapore: Springer).

[16] Astrom.K.J. and Hagglund.T, "Benchmark Systems for PID Control," in IFAC Proceedings on Digital Control: Past, Present and Future of PID Control, 2000, vol. 32, no. 4, pp. 165-166. 